Cronfa - Swansea University Open Access Repository

This is an author produced version of a paper published in :

Journal of Obstetrics and Gynaecology

Cronfa URL for this paper:

http://cronfa.swan.ac.uk/Record/cronfa21302

\title{
Paper:
}

Lewis, M. (2016). Recruitment of pregnant women to an exercise-intervention study. Journal of Obstetrics and Gynaecology

http://dx.doi.org/ 10.3109/01443615.2015.1049988

This article is brought to you by Swansea University. Any person downloading material is agreeing to abide by the terms of the repository licence. Authors are personally responsible for adhering to publisher restrictions or conditions. When uploading content they are required to comply with their publisher agreement and the SHERPA RoMEO database to judge whether or not it is copyright safe to add this version of the paper to this repository. http://www.swansea.ac.uk/iss/researchsupport/cronfa-support/ 


\section{Recruitment of pregnant women to an exercise-intervention study}

Carpenter RE ${ }^{1,2}$, Emery $\mathrm{SJ}^{2}$, Rassi $\mathrm{D}^{3}$, Uzun $\mathrm{O}^{1,4}$, Lewis $\mathrm{MJ}^{1,2^{*}}$

${ }^{1}$ College of Engineering, Swansea University, UK

${ }^{2}$ Abertawe Bro Morgannwg University Health Board, Swansea University, UK

${ }^{3}$ College of Health and Human Sciences, Swansea University, UK

${ }^{4}$ University Hospital of Wales Cardiff, UK

${ }^{*}$ Corresponding author address:

College of Engineering

Swansea University

Talbot Building

Singleton Park

Swansea

SA2 8PP

Tel. +44 1792513043

Email. m.j.lewis@swansea.ac.uk

Keywords: Pregnancy, exercise, recruitment, randomised control trial, longitudinal, study design 


\section{Abstract}

We share here our experience of recruiting pregnant women into an exercise intervention study. Recruitment challenges were anticipated owing to the study design, which required four hospital visits for cardiovascular assessment, a long-term (nine month) commitment, and adherence to a 20-week exercise programme. Fifty-three women were randomised into one of three groups (no-exercise, land exercise or water exercise) using a 2×2×2 design. 744 women were screened at an antenatal clinic, of whom 501 were eligible to participate in the study. 145 women were subsequently approached: 46 (32\%) of whom agreed to participate, 42 (29\%) were interested but then declined, and 57 (39\%) declined outright. Our study design helped recruit pregnant women as it allowed them some choice of group membership. We also noted that the participant-researcher relationship is important in reducing attrition. Our experience provides indications of likely recruitment and attrition rates for future randomised controlled trials of this type. 


\section{Introduction}

The recruitment of participants into longitudinal studies, and thereafter their retention within the study, is challenging. Potential participants are faced with a long-term commitment to the study, and even if this is an acceptable prospect during recruitment, impracticalities can arise at any time during the study's lifetime. Longitudinal studies therefore often result in high dropout rates and/or a failure to recruit the required number of individuals during the designated recruitment period (Oude Rengerink et al., 2010). In a recent study assessing a cohort of 144 UK multi-centre trials (Campbell et al., 2007), less than a third recruited their intended sample size within the planned timeframe, and a third had to extend their recruitment period to achieve sufficient power for hypothesis testing. Lengthening the time of recruitment not only poses issues in terms of project funding but also delays implementing the most current research into clinical practice (Oude Rengerink et al., 2010; van Delft, Schwertner-Tiepelmann, Thakar, \& Sultan, 2013).

Pregnant women are a particularly challenging population with regard to recruitment into research studies, as there is often an imperative timeframe within which to recruit, in order to capture the antenatal stage of interest. At the time of consent (often relatively early in the pregnancy) women will understandably be vigilant regarding both their own welfare and that of the baby. Their willingness to participate in a study might also depend on (1) how demanding the study protocol is (van Delft et al., 2013), (2) on the required commitment to multiple 'testing' sessions during advancing gestation, and (3) on consideration of practical issues such as work and childcare. Unsurprisingly, 
longitudinal antenatal studies often have very high dropout rates - notably in cardiovascular studies, for which attrition rates ranging from $38 \%$ to $73 \%$ have been reported (Bamfo, Kametas, Nicolaides, \& Chambers, 2007; Naqvi \& Elkayam, 2012; Savu et al., 2012).

Numerous methods have been used to recruit pregnant women into research studies but comparisons of the efficacy of different strategies are rarely reported (Tooher, Middleton, \& Crowther, 2008). Research has shown that approaching women directly on a "face-to-face" basis results in the highest rates of recruitment (Gilliss et al., 2001; Manca et al., 2013), but this approach is time-consuming and impractical. A better understanding is needed of the requirements for successful recruitment of pregnant women into research, although this goal is complicated by the individual demands of different protocols and study designs.

Recruitment into intervention studies tends to be more difficult than observational trials (Yancey, Ortega, \& Kumanyika, 2006). Furthermore, the 'randomisation' aspect of randomised controlled trials is often viewed negatively (Lynch, Gorelick, Raman, \& Leurgans, 2001), with participants often preferring a specific intervention or being unwilling to be part of a 'control' group (Oude Rengerink et al., 2010). Implementing an exercise intervention programme during pregnancy complicates the recruitment process further, in part because such intervention is not part of the standard antenatal healthcare pathway. There is also a lot of controversy and confusion amongst pregnant women as to whether they should continue to take part in physical activity during their pregnancy, with many still believing that exercise causes increased risk to the foetus, particularly during early pregnancy (Clarke \& Gross, 2004; Cioffi et al., 2010). Intensive contact with 
participants has been shown to improve participation (Connell, Shaw, Holmes, \& Foster, 2001; Yancey et al., 2006), therefore one strategy for improving recruitment and retention in antenatal exercise intervention studies would be to include frequent (weekly) exercise classes.

The aim of our 'EXPECT' project was to implement a randomised controlled study to examine the influence of regular antenatal exercise on gestational changes in cardiovascular function during and following 'normal' pregnancy. The physiological findings of this project will be presented elsewhere. The purpose of the current report is to share our experiences of recruitment to this project, including a discussion of the challenges we faced and the strategies we adopted.

\section{Methods}

\section{Recruitment and Ethics}

Recruitment for the study took place during the six-month period between October 2012 and April 2013 via the antenatal clinic at Singleton hospital, Swansea. The hospital's Neonatal Intensive Care Unit annual report (2012) showed that 3780 babies were born at our recruitment hospital in 2010, giving us a potential recruitment population of 1890 women in our 6 month recruitment period. Eligible participants were apparently healthy pregnant women aged 18 years or over, with no existing complications of pregnancy at their 12-week dating scan. Potential participants were recruited between 12 and 16 weeks' gestation: (1) through direct contact via the antenatal clinic (during the 12-week dating 
scan or via telephone), (2) via response to posters placed in the antenatal clinic, local GP surgeries, sports centres and antenatal exercise classes, (3) through advertisements placed on the Health Board website and in local newspapers, and (4) via emails sent to university and hospital staff. When telephoning participants, the majority of calls were made in the morning. Each participant was called on at least two occasions, although no message was left if the call went unanswered, as prior contact had not been made with the majority of women. Emails were sent to those who expressed an interest in taking part, to which a study information sheet was attached.

Ethical approval was obtained from the local (South West Wales) NHS Research Ethics Committee. Individuals were ineligible for the study if they had a history of cardiovascular or chronic respiratory problem, sleep apnoea, or central/peripheral nervous system disorder. Eligible individuals were provided with details about the study, including practical requirements and potential risks, and were given one week to consider whether they wished to take part. The protocol was explained to participants in a large amount of detail because of the nature of the measurements (ECG and ICG measurements, explained in further detail below) and the commitment to the exercise intervention required. This is likely to have influenced recruitment and retention for our study. Individuals who did want to participate gave their written consent. They were informed that they were free to leave the study at any time and this would not affect their standard antenatal care. All procedures were conducted in accordance with the Declaration of Helsinki. Recruited participants did not receive any financial incentive for taking part, however reasonable travel costs were reimbursed.

Study Design 
Participants were randomly assigned to one of three groups using a $2 \times 2 \times 2$ randomisation design (Drummond et al., 1994) (Figure 1): (1) the Control Group (members of which did not undertake a formal exercise programme), (2) the Land-based Exercise Group, and (3) the Waterbased Exercise Group. Participants were asked a series of questions to determine the group to which they were assigned. At each stage they had the option to answer 'no' and were free to choose the group to which they preferred to belong (Figure 1).

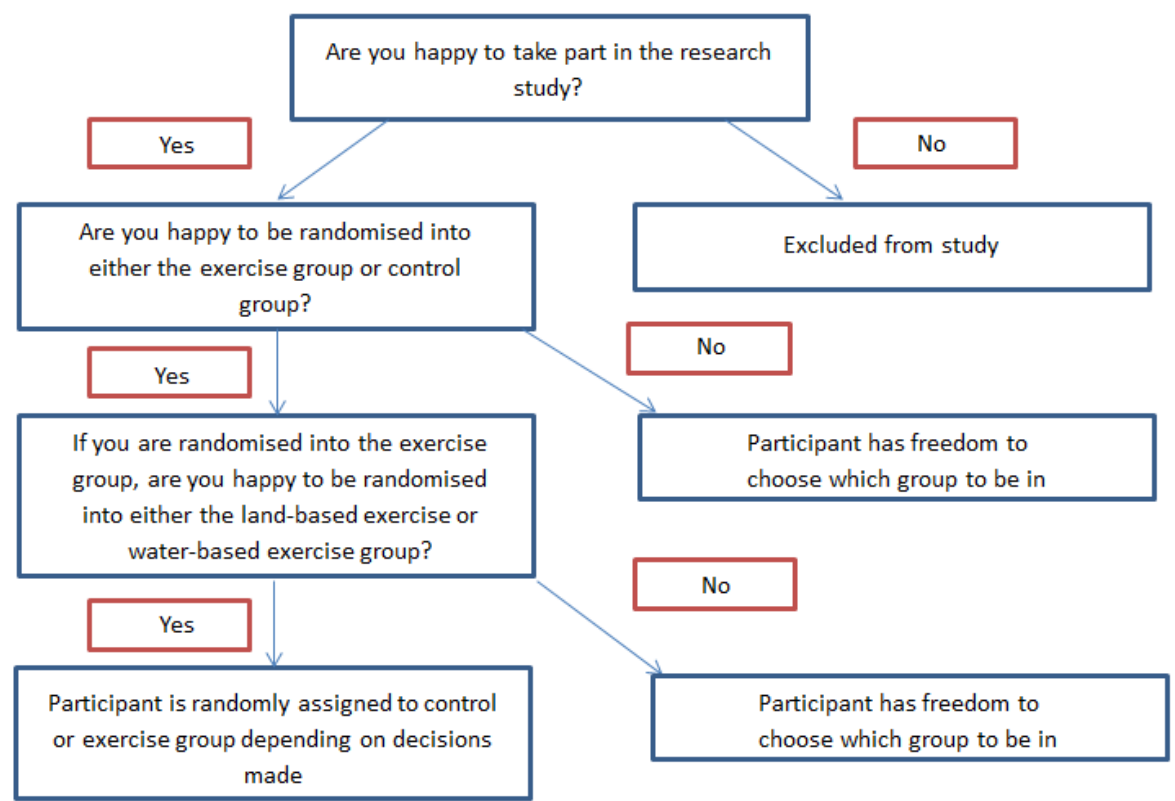


Participants assigned to either of the exercise groups started the corresponding exercise programmes at 20-weeks' gestation and attended weekly classes until full-term or until they felt they could no longer undertake physical activity. All exercise classes were led or supervised by a qualified midwife. Exercise classes on land and in the water were of similar intensities, as previously assessed via heart rate responses.

\section{Physiological Measurement}

Physiological monitoring was carried out on four occasions: at 12-16, 24 -26 and 34-36 weeks gestational age (approximating the end of the three trimesters: $\mathrm{T} 1, \mathrm{~T} 2, \mathrm{~T} 3$ ) and also at 12-weeks post-partum (PP). During each monitoring session participants were asked to perform a series of postural manoeuvres and interventions designed to provoke changes in the cardiovascular and autonomic nervous systems (33 minutes total duration). Continuous cardiovascular and haemodynamic assessment was performed during this time using Holter ECG (Pathfinder/Lifecard Digital system; Spacelabs Medical Ltd., UK) and the Task Force Haemodynamic monitor (CNSystems Medizintechnik GMBH, Austria). Participants completed a Pregnancy Physical Activity Questionnaire (PPAQ) (Chasan-Taber et al., 2004) during each of the three antenatal measurement sessions in order to monitor changes in physical fitness as pregnancy progressed. The questionnaire asked the women to record the amount of time they spent completing a number of activities including household chores and care giving (13 activities), work ( 5 activities), sport and exercise ( 8 activities), travelling (3 activities) and sedentary activities ( 3 activities) (Chasan-Taber et al., 2004). The 
questionnaire took approximately 10 minutes to complete. Follow-up appointments were arranged at the end of each measurement session and participants were called a week before the arranged meeting to confirm that they were still available to attend. A text message was sent on the morning of the measurement session as an additional reminder.

\section{Results}

Recruitment

A total of 744 pregnant women were screened for potential recruitment into the study, accounting for $39.4 \%$ of the potential recruitment population. Of these, $243(33 \%)$ were not eligible to take part in the research as they did not meet the inclusion criteria for participation. The reasons for ineligibility are presented in Figure 2. We were able to contact 145 (29\%) of those women who were eligible to participate, 46 (32\%) of whom agreed to take part, 42 (29\%) women were interested when initially spoken to but unable to contact a week later (lost to follow-up) and 57 (39\%) were not interested in taking part. We asked women who did not wish to take part if they were willing to give reasons for this, and we received the following responses: (1) "time commitments", (2) "child care", (3) "work commitments", (4) "travel arrangements", (5) "already exercise", (6) "unable to make times of exercise classes", (7) "severe morning sickness" and (8) "too overwhelmed by information already given". We were unable to contact 356 (71\%) women who met the inclusion criteria for the study. Of these, 256 (72\%) did not answer our telephone calls, $42(12 \%)$ did not have antenatal records available and $58(16 \%)$ were not contacted by the researchers due 
to time constraints. In addition to this direct contact, a further 8 (15\%) women were recruited via other methods (posters, word of mouth, community midwives \& yoga classes).

Figure 3 shows dropout rates from the study after taking consent. Fifty-three women gave written informed consent and were randomised into the control or exercise groups using the $2 \times 2 \times 2$ design. The control group included 9 participants, the land exercise group included 33 participants and the water exercise group included 11 participants after initial randomisation. Exercise started at 20 weeks of pregnancy and resulted in a drop-out of 17 (32\%) participants. The highest number of participants were lost from the land exercise group ( $n=10,59 \%)$ with fewer losses from the other two groups. Reasons for dropout at this stage were (1) "work commitments", (2) "child care", (3) "lost to follow up", (4) "premature birth" (at 23 weeks gestation), (5) "injury" (unspecified by participant), (6) "moved out of area and receiving health care elsewhere".

Thirty-six participants completed physiological measurements between 24 and 26 weeks. Drop-out between T2 and T3 was $16 \%$ and this was due to medical complications or loss of contact. No women were lost from the control group. Thirty participants completed physiological measurements between 34 and 36 weeks. 16\% of women were also lost between the final antenatal measurement and the post-partum period and this was because of loss of follow up $(n=3,60 \%)$, another pregnancy $(n=1)$ and hospitalisation $(n=1)$. Twenty-five participants completed all four measurements in the study. Participant characteristics of those initially recruited and those who completed all trials can be seen in Table I. Activity levels for those recruited to the control and exercise groups at the initial measurement are shown in Table 2. There was 
no difference $(p=0.112)$ in total activity between those recruited for the control and exercise groups. The study resulted in a $53 \%$ drop-out rate in total. 


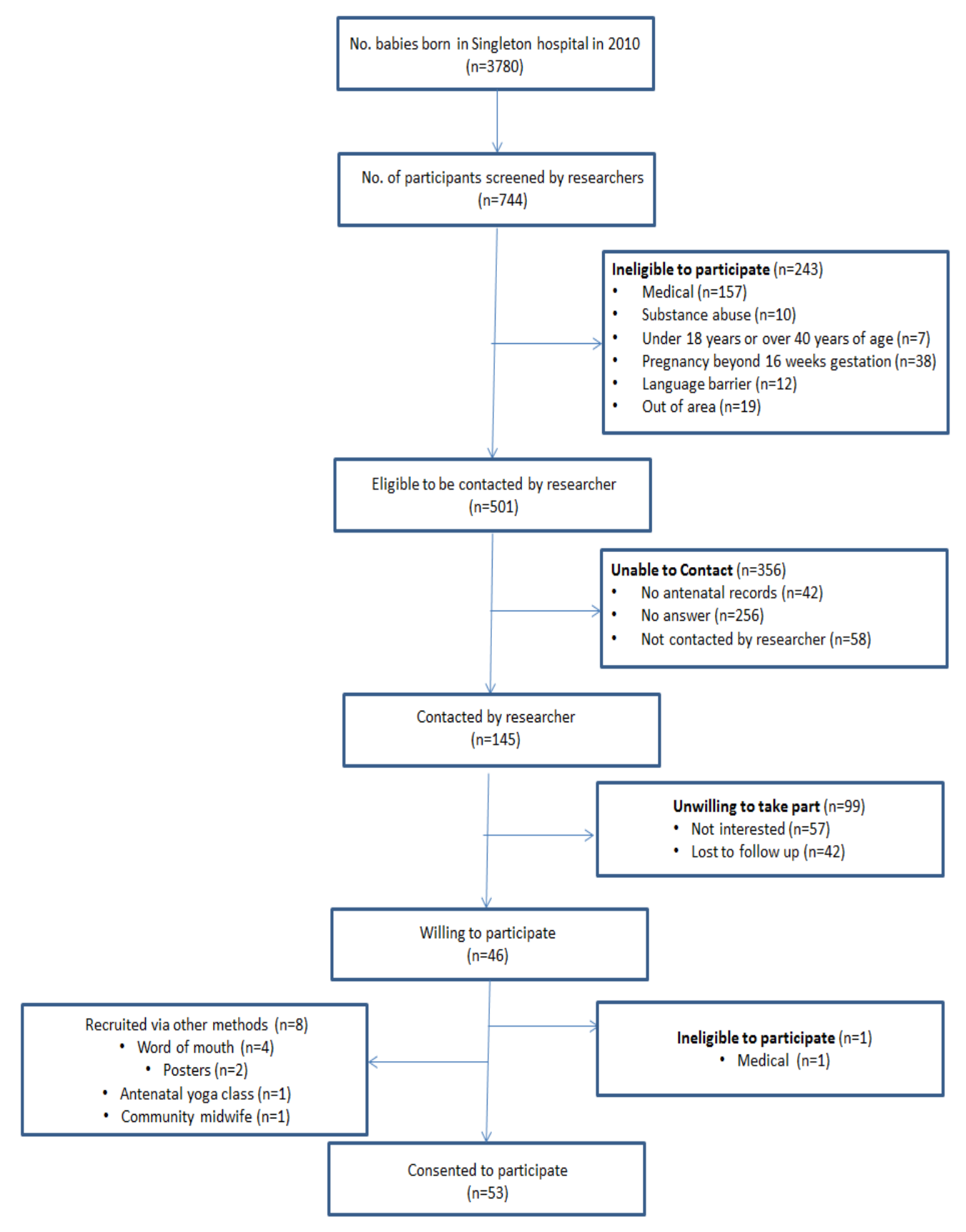


Figure 2: Flow diagram of the recruitment process 


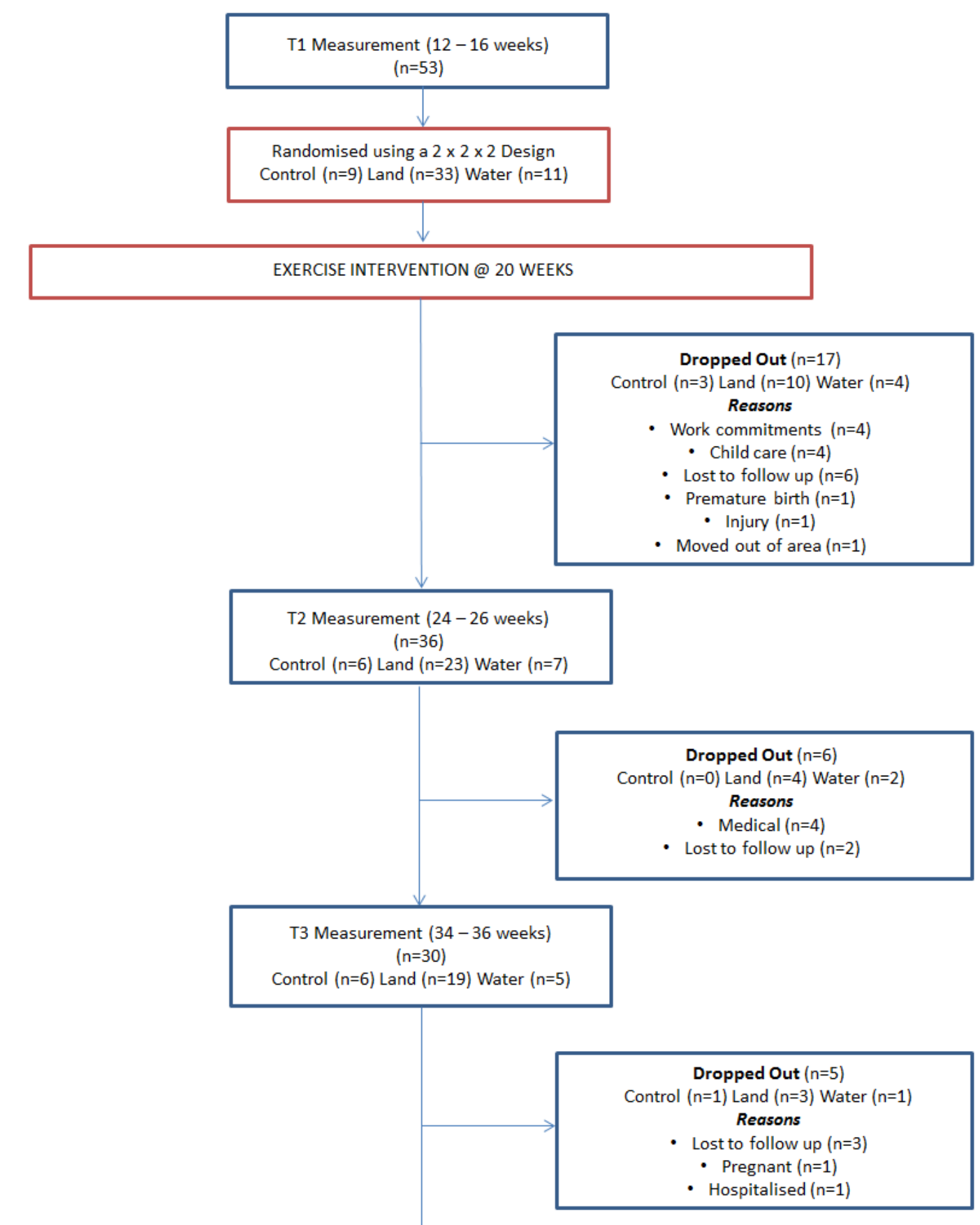




\section{Participant Characteristics}

Table 1. Participant characteristics

\begin{tabular}{|c|c|c|c|c|}
\hline & \multicolumn{2}{|c|}{ Initially Recruited (n=53) } & \multicolumn{2}{|c|}{ Completed Trials $(n=25)$} \\
\hline & $\mathbf{N}$ & $\%$ & $\mathbf{n}$ & $\%$ \\
\hline \multicolumn{5}{|c|}{$\begin{array}{l}\text { Maternal Age at Initial } \\
\text { Measurement (Years) }\end{array}$} \\
\hline $19-24$ & 12 & 23 & 4 & 16 \\
\hline $25-29$ & 18 & 34 & 7 & 28 \\
\hline $30-34$ & 19 & 36 & 11 & 44 \\
\hline $35-39$ & 3 & 6 & 2 & 8 \\
\hline $40+$ & 1 & 2 & 1 & 4 \\
\hline \multicolumn{5}{|l|}{$\begin{array}{c}\text { BMI at Initial } \\
\text { Measurement }\left(\mathrm{kg} \cdot \mathrm{m}^{-2}\right)\end{array}$} \\
\hline$<18.5$ & 0 & 0 & 0 & 0 \\
\hline $18.5-24.9$ & 27 & 51 & 12 & 48 \\
\hline $25.0-29.9$ & 10 & 19 & 4 & 16 \\
\hline$>30$ & 16 & 30 & 9 & 36 \\
\hline \multicolumn{5}{|l|}{ Parity } \\
\hline Nulliparous & 20 & 38 & 12 & 48 \\
\hline Primi/Multiparous & 33 & 62 & 13 & 52 \\
\hline
\end{tabular}




\begin{tabular}{ccc|cc}
$\begin{array}{c}\text { Previous (Prior to } \\
\text { pregnancy) } \\
\text { Current }\end{array}$ & 17 & 32 & 11 & 44 \\
\hline
\end{tabular}

Table 2 Activity levels (Mean \pm SEM) assessed using the Pregnancy Physical Activity Questionnaire (PPAQ) for the control and exercise groups during the first trimester (T1) and third trimester (T3) and the T3 vs. T1 change.

\begin{tabular}{|c|c|c|c|c|c|c|c|c|c|}
\hline \multirow{2}{*}{ Activity } & \multicolumn{3}{|c|}{ T1 } & \multicolumn{3}{|c|}{ T3 } & \multicolumn{3}{|c|}{ Change (T3-T1) } \\
\hline & Control & Exercise & $\mathbf{p}$ & Control & Exercise & $\mathbf{p}$ & Control & Exercise & $\mathbf{p}$ \\
\hline $\begin{array}{l}\text { Total activity } \\
\left(\text { MET-h.week }{ }^{-1}\right)\end{array}$ & $354.1 \pm 32.9$ & $238.0 \pm 34.5$ & 0.070 & $280.8 \pm 37.4$ & $204.7 \pm 21.8$ & 0.089 & $-73.3 \pm 54.5$ & $-33.3 \pm 17.9$ & 0.371 \\
\hline $\begin{array}{l}\text { Sedentary activity } \\
\left(\text { MET-h.week }{ }^{-1}\right)\end{array}$ & $66.6 \pm 25.5$ & $88.7 \pm 9.5$ & 0.322 & $57.8 \pm 19.4$ & $76.5 \pm 8.1$ & 0.300 & $-8.9 \pm 13.3$ & $-12.2 \pm 5.0$ & 0.775 \\
\hline $\begin{array}{l}\text { Light intensity } \\
\left(\text { MET-h. } \text { week }^{-1}\right)\end{array}$ & $124.0 \pm 20.2$ & $78.7 \pm 13.2$ & 0.086 & $87.7 \pm 18.7$ & $83.7 \pm 16.7$ & 0.894 & $-36.4 \pm 28.8$ & $5.0 \pm 9.6$ & 0.093 \\
\hline $\begin{array}{l}\text { Moderate intensity } \\
\left(\text { MET-h.week }{ }^{-1}\right)\end{array}$ & $156.0 \pm 34.7$ & $66.5 \pm 26.4$ & 0.080 & $129.6 \pm 20.9$ & $42.7 \pm 9.0$ & $<0.0005$ & $-26.5 \pm 38.3$ & $-23.8 \pm 18.7$ & 0.945 \\
\hline $\begin{array}{l}\text { Vigorous intensity } \\
\left(\mathrm{MET}-\mathrm{h} \cdot \text { week }^{-1}\right)\end{array}$ & $7.5 \pm 3.9$ & $4.1 \pm 1.5$ & 0.333 & $5.9 \pm 3.4$ & $1.9 \pm 1.0$ & 0.311 & $-1.6 \pm 4.4$ & $-2.2 \pm 0.9$ & 0.897 \\
\hline $\begin{array}{l}\text { Household activity } \\
\left(\mathrm{MET}-\mathrm{h} \cdot \text { week }^{-1}\right)\end{array}$ & $182.5 \pm 43.4$ & $63.0 \pm 15.6$ & 0.004 & $129.8 \pm 29.0$ & $67.5 \pm 15.5$ & 0.059 & $-52.8 \pm 37.1$ & $4.5 \pm 8.4$ & 0.042 \\
\hline  & $62.3 \pm 18.4$ & $93.3 \pm 22.5$ & 0.432 & $44.3 \pm 20.2$ & $66.9 \pm 8.2$ & 0.288 & $-18.0 \pm 13.8$ & $-26.5 \pm 16.9$ & 0.773 \\
\hline $\begin{array}{l}\text { Sport/Exercise } \\
\left(M E T-h \cdot \text { week }^{-1}\right)\end{array}$ & $30.0 \pm 8.4$ & $16.0 \pm 6.4$ & 0.244 & $19.4 \pm 8.4$ & $17.1 \pm 5.2$ & 0.818 & $-10.5 \pm 8.9$ & $1.1 \pm 2.5$ & 0.266 \\
\hline
\end{tabular}

The questionnaire was only completed by a subset of participants (Control, $n=5$; Exercise, $n=14$ )

MET = Metabolic Equivalent; MET-h = MET hours; $1 \mathrm{MET}=1 \mathrm{kcal} \cdot \mathrm{kg}^{-1} \cdot \mathrm{h}^{-1}$ 
months. We believe our experience will provide other researchers with useful indicators of

likely recruitment numbers and attrition rates when undertaking this type of randomised controlled trial.

\section{Timing of Recruitment}

Participants in our study were recruited between 12 and 16 weeks gestation, around the time of their dating scan. Ideally all physiological studies regarding pregnancy would recruit prior to conception, as the most marked changes in maternal physiology take place prior to 6 weeks gestation (Duvekot, Cheriex, Pieters, Menheere, \& Peeters, 1993; Mahendru, Everett, Wilkinson, Lees, \& McEniery, 2014). This, however, provides problems of its own the main issue being funding, as well as staffing, time constraints on the recruitment window and unpredictability of conception. Early pregnancy is a similarly difficult time to recruit mothers into research studies: many women are unaware that they are pregnant at this stage, or they might not have disclosed their pregnancy to many people due to the high risk of miscarriage. However, recruitment at 12 weeks in this study was also not without problems; with many women finding the addition of the research study to the already vast amount of information they had been provided with as 'too overwhelming' to even consider 
necessary to achieve meaningful results, would be a useful approach.

\section{Methods of Recruitment}

We used several different methods to recruit pregnant mothers in our study. The main method was via the antenatal clinic, either by speaking to women in person after their dating scan or by screening them using their medical records and then 'blind calling' them by telephone. Despite this, we only managed to screen 744 (39.4\%) pregnant women. We still, therefore, had the potential to screen and potentially contact double the number of participants we did, despite the numerous methods we used for recruitment. Initially, all pregnant women were screened by the midwives in the antenatal clinic rather than by the research team. Many of the midwives were reluctant to promote our study, owing to a lack of understanding regarding the implications of our research and their already busy schedules. This meant that potential participants were not identified and were therefore not contacted to enquire about possible participation. Providing a leaflet with information regarding our study at the initial midwifery appointment was not considered appropriate owing to the plethora of information given to patients at this time. Future studies should therefore take time to 'sell' their research ideas and recruitment processes to the antenatal 
researchers from the University, calls tended to be hung up or dismissed immediately,

whereas those introduced as researchers from the antenatal clinic were better received and participants were more likely to listen to potential benefits and the impact of the research.

Calls from a mobile tended to be ignored whilst land-line numbers had the greatest chance of being answered. $71 \%$ of telephone calls to those eligible to take part in the study were left unanswered. The time of day when the calls were made is likely to have substantially influenced this high rate of 'non-contactability'. A small proportion (15\%) of women were recruited using other methods such as poster advertisement and via 'word of mouth' from existing participants. We anticipated that strategically located posters would gain maximum exposure for the study based on the success of other studies (Pastore \& Dalal, 2009), but this was not borne out by recruitment success. Of the eight women recruited via these methods, $63 \%$ dropped out of the study - a higher proportion than the overall drop-out rate. Clearly the methods used to optimise recruitment into, and retention within, an antenatal study need careful consideration and planning. 
recruitment into our study owing to its nature (physical exercise intervention). There is still a

lot of confusion amongst pregnant women as to whether they should continue to take part

in physical activity during their pregnancy and many still believe that exercising causes

increased risk for the foetus, particularly during early pregnancy (Clarke \& Gross, 2004;

Cioffi et al., 2010). It has been reported that two out of three British women reduce their

physical activity levels by the $18^{\text {th }}$ week of gestation (Liu et al., 2011) despite

recommendations and guidelines for exercise during pregnancy being available (Royal

College Obstetricians and Gynaecologists, 2006). Pre-enrolment explanation of the

potential benefits of antenatal physical activity for mothers and their babies is likely to have

increased the rate of recruitment and reduced the rate of drop out. Unfortunately this is

difficult to achieve in practice owing to the limited time available during the recruitment

'window'. Participants for antenatal studies are often at an early stage of gestation to

enable longitudinal assessment and it is important that they understand the long-term

commitment that this requires. It is therefore particularly important in this type of research

that women have adequate time to discuss the potential implications of participation with

their families, friends and clinicians. Following initial contact, we allowed one week for

participants to reflect on the study and to decide whether they would like to take part. We

felt that this was adequate time for women to make a decision, although almost a third 
to randomly assign women to an exercise group and to ask them to begin exercising during

pregnancy. A number of issues were pertinent in this regard: (1) participants might not have exercised previously, (2) they might not be comfortable taking part in group exercise, (3) they might be conscious of the physical changes in their bodies and so might not be comfortable wearing swimming costumes or gym clothes. We therefore designed a study that involved randomisation but that also provided participants with the freedom to effectively choose to which group they preferred to be assigned (Figure 1). We adopted a $2 \times 2 \times 2$ randomisation design, which meant that participants could either be randomised to any of the three groups, to one of the two intervention groups, to any single intervention group or to none of the groups (Drummond et al., 1994). The use of 'no choice' randomisation study designs is not always well-received by the potential participant (Lynch et al., 2001; Oude Rengerink et al., 2010), so our approach might encourage participation and reduce drop-out rates in this type of longitudinal intervention study. Out of the fiftythree women who consented to take part in the study, none allowed themselves to be truly randomised into the control or exercising groups, emphasising the importance of our randomised design. Despite the advantages of our recruitment approach, a limitation of this study design is the potential for bias in the data, with previously active women tending to select membership of the exercising groups and sedentary women selecting the control 
High drop-out rates are associated with longitudinal antenatal studies, particularly in

cardiovascular studies (Bamfo et al., 2007) for which attrition rates ranging from $38-73 \%$ have been reported (Bamfo et al., 2007; Naqvi \& Elkayam, 2012; Savu et al., 2012). The highest drop-out rates in these studies were observed in the post-partum period, leading authors to instead favour the recruitment of non-pregnant controls with which to compare their pregnancy data. Consistent with previous reports, our study had a $53 \%$ attrition rate, with the majority of participants (32\%) leaving the study at 20 weeks of pregnancy (the point at which some were about to start the exercise intervention). The main reasons given for drop out at this stage were 'work commitments' and 'child care problems' ( $n=8,47 \%)$. We can only attribute this large rate of attrition to a lack of appreciation of the necessary commitment that would need to be given to the study at this stage.

Potential participants in antenatal research need a very clear description and understanding of their involvement; this is perhaps even more important for pregnant mothers than in other research populations owing to the longitudinal nature of antenatal studies. Previous studies have observed the highest drop-out rates during the post-partum period, considered to be the result of a loss of contact between the participant and researcher (Bamfo et al., 
importance to the participants (such as pain management, pelvic floor exercises and

breastfeeding), these being delivered by our midwifery and obstetrics/gynaecology team.

We provided women with regular telephone reminders about follow-up appointments and ensured that we were flexible with our availability, offering testing sessions throughout the day and the evening for women that worked. Intensive follow-up and contact with subjects has been shown to improve participation and retention in studies (Yancey et al., 2006).

Developing this relationship may have meant the participants felt more of an obligation to come back and complete the study. Participants did not receive any financial incentive for taking part, although we did offer to reimburse reasonable travel costs. Of the fifty three participants initially recruited, only one participant asked for travel cost reimbursement.

\section{Conclusion}

Our experience of recruitment and retention of pregnant women into a physical exercise intervention study has provided useful insight into these processes. We designed a study that enabled participants to have the freedom to choose which arm of the randomised trial they took part in. This encouraged participation amongst women and may have reduced the rate of dropout in our study. It therefore should be considered for future trials of a similar 


\section{Declaration of Interest}

The authors report no conflicts of interest. The authors alone are responsible for the content and writing of the paper. R Carpenter received a NISCHR (Welsh Government National Institute for Social Care and Health Research) PhD studentship, and The Cooperative Pharmacy (UK) provided financial support for project consumables.

\section{References}

Bamfo, J. E., Kametas, N. A., Nicolaides, K. H., \& Chambers, J. B. (2007). Maternal left ventricular diastolic and systolic long-axis function during normal pregnancy. Eur J Echocardiogr, 8(5), 360-368. doi: 10.1016/j.euje.2006.12.004

Campbell, M. K., Snowdon, C., Francis, D., Elbourne, D., McDonald, A. M., Knight, R., ... group, S. (2007). Recruitment to randomised trials: strategies for trial enrollment and participation study. The STEPS study. Health Technol Assess, 11(48), iii, ix-105.

Chasan-Taber, L., Schmidt, M. D., Roberts, D. E., Hosmer, D., Markenson, G., \& Freedson, P. S. (2004). Development and validation of a Pregnancy Physical Activity Questionnaire. Med Sci Sports Exerc 36(10): 1750-1760

Cioffi, J., Schmied, V., Dahlen, H., Mills, A., Thornton, C., Duff, M., . . Kolt, G. S. (2010). Physical activity in pregnancy: women's perceptions, practices, and influencing factors. J Midwifery Womens Health, 55(5), 455-461. doi: 10.1016/j.jmwh.2009.12.003

Clarke, P. E., \& Gross, H. (2004). Women's behaviour, beliefs and information sources about physical exercise in pregnancy. Midwifery, 20(2), 133-141. doi: 10.1016/j.midw.2003.11.003

Connell, C. M., Shaw, B. A., Holmes, S. B., \& Foster, N. L. (2001). Caregivers' attitudes toward their family members' participation in Alzheimer disease research: implications for recruitment and retention. Alzheimer Dis Assoc Disord, 15(3), 137-145.

Drummond, N., Abdalla, M., Beattie, J. A. G., Buckingham, J. K., Lindsay, T., Osman, L. M., Ross, S. J., Roy-Chaudhury, A., Russell, I., Turner, M., Friend, J. A. R., Legge, J. S., Douglas, J.G. (1994).

Effectiveness of routine self monitoring of peak flow in patients with asthma. BMJ, 308, 559564. doi: http://dx.doi.org/10.1136/bmj.308.6928.564

Duvekot, J. J., Cheriex, E. C., Pieters, F. A., Menheere, P. P., \& Peeters, L. H. (1993). Early pregnancy changes in hemodynamics and volume homeostasis are consecutive adjustments triggered by a primary fall in systemic vascular tone. Am J Obstet Gynecol, 169(6), 1382-1392. 
study of maternal cardiovascular function from preconception to the postpartum period. $J$ Hypertens, 32(4), 849-856. doi: 10.1097/HJH.0000000000000090

Manca, D. P., O'Beirne, M., Lightbody, T., Johnston, D. W., Dymianiw, D. L., Nastalska, K., ... team, A. s. (2013). The most effective strategy for recruiting a pregnancy cohort: a tale of two cities. BMC Pregnancy Childbirth, 13, 75. doi: 10.1186/1471-2393-13-75

Naqvi, T. Z., \& Elkayam, U. (2012). Serial echocardiographic assessment of the human heart in normal pregnancy. Circ Cardiovasc Imaging, 5(3), 283-285. doi: 10.1161/CIRCIMAGING.112.974808

Neonatal Intensive Care Unit annual report. (2010). Children and Young People Committee NN01. Inquiry into Neonatal Care. Accessed Online: http://www.assemblywales.org/bushome/research/bus-assembly-research-publications/health-socialcare/search.htm?q=neonatal+annual+report (22 ${ }^{\text {nd }}$ May 2014).

Oude Rengerink, K., Opmeer, B. C., Logtenberg, S. L., Hooft, L., Bloemenkamp, K. W., Haak, M. C., . . $\mathrm{Mol}$, B. W. (2010). IMproving PArticipation of patients in Clinical Trials--rationale and design of IMPACT. BMC Med Res Methodol, 10, 85. doi: 10.1186/1471-2288-10-85

Pastore, L. M., \& Dalal, P. (2009). Recruitment strategies for an acupuncture randomized clinical trial of reproductive age women. Complement Ther Med, 17(4), 229-235. doi: 10.1016/j.ctim.2009.03.004

Rodger, M. A., Makropoulos, D., Walker, M., Keely, E., Karovitch, A., \& Wells, P. S. (2003). Participation of pregnant women in clinical trials: will they participate and why? Am J Perinatol, 20(2), 69-76. doi: 10.1055/s-2003-38318

Royal College of Obstetricians and Gynaecologists. (2006). Exercise in pregnancy. RCOG Statement No. 4 - January 2006. Accessed Online: http://www.rcog.org.uk/womens-health/clinicalguidance/exercise-pregnancy (22 ${ }^{\text {nd }}$ May 2014).

Savu, O., Jurcuţ, R., Giuşcă, S., van Mieghem, T., Gussi, I., Popescu, B. A., . . Voigt, J. U. (2012). Morphological and functional adaptation of the maternal heart during pregnancy. Circ Cardiovasc Imaging, 5(3), 289-297. doi: 10.1161/CIRCIMAGING.111.970012

Snowdon, C., Elbourne, D., \& Garcia, J. (2006). "It was a snap decision": parental and professional perspectives on the speed of decisions about participation in perinatal randomised controlled trials. Soc Sci Med, 62(9), 2279-2290. doi: 10.1016/j.socscimed.2005.10.008

Tooher, R. L., Middleton, P. F., \& Crowther, C. A. (2008). A thematic analysis of factors influencing recruitment to maternal and perinatal trials. BMC Pregnancy Childbirth, 8, 36. doi: 10.1186/1471-2393-8-36

van Delft, K., Schwertner-Tiepelmann, N., Thakar, R., \& Sultan, A. H. (2013). Recruitment of pregnant women in research. J Obstet Gynaecol, 33(5), 442-446. doi: 10.3109/01443615.2013.767787

Yancey, A. K., Ortega, A. N., \& Kumanyika, S. K. (2006). Effective recruitment and retention of minority research participants. Annu Rev Public Health, 27, 1-28. doi: 10.1146/annurev.publhealth.27.021405.102113 
